\title{
Comparative Analysis of Surface Quality Prediction Models
}

\author{
Radoslav Vučurević ${ }^{\# 1}$, Zdravko Krivokapić ${ }^{* 2}$, Radislav Brđanin ${ }^{\# 3}$ \\ "University of East Sarajevo, Production and Management Faculty Trebinje \\ Stepe Stepanovića bb, 89101 Trebinje, Bosnia and Herzegovina \\ ${ }^{1}$ radoslav.vucurevic@gmail.com \\ ${ }^{3}$ radislavbrdjanin@gmail.com \\ *University of Montenegro, Faculty of Mechanical Engineering \\ Džordža Vašingtona bb, 81000 Podgorica, Montenegro \\ 2zdravkok@ac.me
}

\begin{abstract}
The paper presents a comparative analysis of the models for predicting machined surface quality developed by the application of multiple regression and artificial neural networks. The models were developed using experimental data for the mean arithmetic deviation of surface roughness and the axial cutting force obtained by implementing the Taguchi experiment plan. Comparative analysis of the models has shown that artificial neural networks give the best results in terms of predicting the mean arithmetic deviation of surface roughness on the basis of process parameters and axial cutting force.
\end{abstract}

Keyword - models, axial force, prediction, surface roughness

\section{INTRODUCTION}

Experimental research seeks to establish dependence between quality of the machined surface and parameters of the cutting process. Prediction of the machined surface quality through the mean arithmetic deviation of the surface roughness $\left(R_{a}\right)$ is made by using a multiple regression mathematical model and by applying models based on artificial neural networks that connect machining process input parameters with the quality of the machined surface.

Çiçek, Kivak and Samtaş [1], using the Taguchi experiment design in a drilling operation on austenitic stainless steel AISI 316 with high-speed steel (HSS) twist drills, conventionally and cryogenic, varying feed $f$ $(\mathrm{mm} / \mathrm{o})$ and the cutting speed $v_{c}(\mathrm{~m} / \mathrm{min})$ at two levels, develop a regression model that combines the indicated parameters with the machined surface quality through the mean arithmetic deviation $R_{a}(\mu m)$, with a $96,3 \%$ coefficient of determination.

Rodrigues et al. [2] use a regression analysis to obtain a mathematical model that links the spindle speed $n$ $(\mathrm{rpm})$, feed $f(\mathrm{~mm} / \mathrm{rev})$ and cutting depth $a(\mathrm{~mm})$ with the machined surface quality through the mean arithmetic deviation $R_{a}(\mu \mathrm{m})$ by conducting a full experiment plan and varying of the mentioned parameters at three levels in a turning operation on structural steel with high-speed steel (HSS) tools. The adjusted coefficient of determination in this case is $66,1 \%$ which indicates a strong connection between the machined surface quality and the mentioned parameters.

Raghunandan, Bhandarkar and Pankaj [3], based on the data obtained using the Taguchi experiment design in a truning operation on EN-19 material with cemented carbide inserts, come up with a model linking a mean arithmetic deviation of surface roughness $R_{a}(\mu \mathrm{m})$, cutting speed $v_{c}(\mathrm{~m} / \mathrm{min})$, feed $f(\mathrm{~mm} / \mathrm{rev})$ and cutting depth $a$ $(\mathrm{mm})$. The adjusted coefficient of determination, which describes the given connection, in this case is $52,8 \%$.

Ficici, Koksal and Karacadag [4] investigate the effect of tool modification (twist drill cutting edge grinding in $\mu \mathrm{m})$, cutting speed $v_{c}(\mathrm{~m} / \mathrm{min})$ and feed $f(\mathrm{~mm} / \mathrm{rev})$, using Taguchi experiment design in a drilling operation on austenitic stainless steel AISI 304 with high-speed steel (HSS) twist drills. Development of the regression model links the stated parameters with the machined surface quality through the mean arithmetic deviation $R_{a}(\mu m)$ and the implementation of the confirmatory experiment using the optimal combination of parameters find that the prediction error is $4,34 \%$.

Rashid and Lani [5], in addition to using multiple regression to obtain a mathematical model, use artificial neural networks for predicting surface roughness in a milling operation on aluminum. By performing the experiment, using a complete factorial plan, they develop the models that connect surface roughness expressed through the mean arithmetic deviation of the roughness profile $R_{a}(\mu \mathrm{m})$, the spindle speed $n(\mathrm{rpm})$, the velocity of the auxiliary motion $v_{f}(\mathrm{~mm} / \mathrm{min})$ and depth of cut $a(\mathrm{~mm})$. The developed mathematical model gives the result with an average error of $13,3 \%$, while the artificial neural network shows more favorable results with $6,42 \%$ of the average error. 
Šimunović, Šarić and Lujić [6] apply artificial neural networks for predicting the surface roughness of a workpiece of steel Č.4730 (EN 25CrMo4), machined by turning, using as input parameters the type of material, type of tool, depth of cut, feed and spindle speed. This model, based on artificial neural networks, gives results with an average error of less than $5 \%$ in the light of the data used to train, validate and test the possibilities of the model.

Konanki and Sadineni [7], by conducting the Taguchi experiment plan and using input data for the cutting speed $v_{c}(\mathrm{~m} / \mathrm{min})$, spindle speed $n(\mathrm{rpm})$ and depth of cut $a(\mathrm{~mm})$ varied on three levels in a turning operation on AA 6351 alloy, develop a model for predicting surface roughness on the basis of artificial neural networks using a mean arithmetic deviation $R_{a}(\mu \mathrm{m})$ with an average test error of $2,24 \%$.

These models give a good approximation of the experimental results, but do not take into account the impact of the tool wear on the quality of the machined surface.

Nedić, Tadić and Đorđević [8], on the basis of experimental investigationsin turning and drilling operations on softly annealed steels with pearlite-ferrite structure, come to a polynomial dependence in the form of a thirddegree polynom between the mean arithmetic deviation of the surface roughness $R_{a}(\mu \mathrm{m})$ and machining tools wear $V B(\mathrm{~mm})$.

Spaić and Marinović [9], by using the artificial neural networks based on the experimental results obtained in a drilling operation on steel C.4732 (EN 42CrMo4) with high-speed steel twist drills, establish a model for the axial drilling force $F_{3}(N)$ dependent on the tool wear width $V B(\mathrm{~mm})$. They demonstrate that artificial neural networks can be adequately used to predict the axial drilling force as a carrier of information on the tool wearing.

$\mathrm{Xu}$, Hiroyuki and Wei [10] show that tool wear $V B(\mathrm{~mm})$ in a drilling operation on aluminum alloys can be predicted by means of artificial neural networks by using process input parameters such as depth of cut $a(\mathrm{~mm})$, spindle speed $n(\mathrm{rpm})$ and feed $f(\mathrm{~mm} / \mathrm{rev})$, adding the values of measurable process parameters such as axial cutting force $F_{3}(\mathrm{~N})$ and torque $M(\mathrm{Nm})$.

Considering the aforesaid, it appears possible to develop multiple regression models and a model based on the application of artificial neural networks that will include both the process input parameters (the speed, the feed, the depth of cut) and measurable machining process parameters associated with machining tools wear (the force, the torque etc.) at the same time enabling a comparative analysis and reaching a conclusion on the character of the error of individual models.

\section{Multiple Regression Models}

A multiple regression model successfully describes interdependence of the phenomena in reality, and the aim of multiple regression is to make predictions of dependent variable variations based on the estimated model for different combinations of explanatory variables values [11].

Multiple linear regression model which is applied in cases when there are several explanatory (independent or regression) variables can be written in the form:

$$
y=\beta_{0}+\beta_{1} x_{1}+\beta_{2} x_{2}+\ldots+\beta_{k} x_{k}+e .
$$

In this model, the variable $y$ is the dependent variable, $x_{1}, x_{2}, \ldots, x_{k}$ are independent variables, $\beta_{0}, \beta_{1}, \beta_{2}, \ldots, \beta_{k}$ are the regression coefficients (the parameters of the model to be determined), and $e$ is a random variable.

Given a statistical (random) sample of size $n$ to be used for establishing the relationship between dependent variable $y$ and the independent variables $x_{1}, x_{2}, \ldots, x_{k}$, the following $n$ equation corresponds to the above equation:

$$
y_{i}=\beta_{0}+\beta_{1} x_{1 i}+\beta_{2} x_{2 i}+\ldots+\beta_{k} x_{k i}+e_{i}, \quad i=1, \ldots . n .
$$

The basic task of forming the regression model is reduced to the estimate of unknown parameters of the model $\beta_{0}, \beta_{1}, \beta_{2}, \ldots, \beta_{k}$, to obtaining the estimated values of the parameters $b_{0}, b_{1}, b_{2}, \ldots, b_{k}$ by the least squares method, and to forming the model as follows:

$$
\hat{y}=b_{0}+b_{1} x_{1}+b_{2} x_{2}+\ldots+b_{k} x_{k} .
$$

To determine the model adaptation to empirical data, a standard error of regression and a coefficient of determination is used where the standard error of regression $s$ represents the estimate of the random error $\sigma$ standard deviation, while the coefficient of determination $R^{2}$ shows the percentage of dependent variable variations explained by the combined impact of the explanatory variables included in the model [11].

The standard error of regression $s$, as the absolute measure of representativity expressed in the units of dependent variable $y$, is determined as the square root of the estimated value of the random error $\hat{\sigma}^{2}$ variance and the number of degrees of freedom $n-(k+1)$ : 


$$
s=\sqrt{\hat{\sigma}^{2}}=\sqrt{\frac{\sum_{i=1}^{n} e_{i}^{2}}{n-(k+1)}},\left(e_{i}=\hat{y}_{i}-y_{i}\right) .
$$

The coefficient of determination $R^{2}$, as the relative measure of representativity of the model obtained, is a quantitative measure of the linear dependence degree of the dependent variable $y$ and several independent variables $x_{1}, x_{2}, \ldots, x_{k}$, and is determined as the ratio of regression variance and total variance [12]:

$$
R^{2}=\frac{\sum_{i=1}^{n}\left(\hat{y}_{i}-\bar{y}\right)^{2}}{\sum_{i=1}^{n}\left(y_{i}-\bar{y}\right)^{2}} .
$$

When the number of data in a random sample is small and several independent variables $x_{1}, x_{2}, \ldots, x_{k}$, are observed, the coefficient of determination is high thus requiring its correction by taking into account the number of variables and the sample size $n$. This is done using the adjusted coefficient of determination $\bar{R}^{2}$, defined as [11]:

$$
\bar{R}^{2}=1-\frac{n-1}{n-(k+1)}\left(1-R^{2}\right) .
$$

The adjusted coefficient of determination $\bar{R}^{2}$, which is always less than the coefficient of determination of $R^{2}$ whose value approaches the value of the coefficient of determination by increasing the number of data in the sample, in this case represents a more precise relative measure of the model's representativeness.

In addition to determining the standard error of regressions $s$ and the coefficient of determination $R^{2}$, determination of the sense of the dependent variable $y$ estimation based on each of the independent variable $x_{1}$, $x_{2}, \ldots, x_{k}$ requires significance testing of the estimated parameters $b_{0}, b_{1}, b_{2}, \ldots, b_{k}[13]$.

The precondition for testing significance of the parameters is to calculate the standard error of a parameter $S_{b_{j}}, j=1, \ldots, k$ :

$$
S_{b_{j}}=\sqrt{\frac{s^{2}}{\sum x_{j i}^{2}-n \bar{x}_{j}^{2}}} .
$$

The statistical significance of the estimated regression parameters is determined on the basis of the limit table $t$-value and the calculated value $t_{j}$ :

$$
t_{j}=\frac{b_{j}}{S_{b_{j}}} .
$$

By reading the limit values from the $t$-tables for degree of freedom $n$ - $(k+1)$ and significance level $p$ one can draw a conclusion on the statistical significance of the evaluated parameters and the sense for estimation of the dependent variable $y$ on the basis of an independent variable $x_{j}$. In case of $\left|t_{j}\right|<t$ the estimate of the dependent variable $y$ makes sense.

A multiple nonlinear regression model which is applied in cases when there are several independent variables can be written in the form:

$$
y=\beta_{0} \cdot x_{1}^{\beta_{1}} \cdot x_{2}^{\beta_{2}} \cdot \ldots \cdot x_{k}^{\beta_{k}} \cdot e .
$$

A nonlinear regression model is reduced by the logarithmic transformation to the linear regression model of the form:

$$
\log y=\log \beta_{0}+\beta_{1} \log x_{1}+\beta_{2} \log x_{2}+\ldots+\beta_{k} \log x_{k}+\log e .
$$

In the given model, the variable $\log y$ represents the dependent variable, and the $\log x_{1}, \log x_{2}, \ldots, \log x_{k}$ are independent variables.

Given a random sample of size $n$ to be used for establishing relationship between the dependent variable $y$ and the independent variables $x_{1}, x_{2}, \ldots, x_{k}$, the following $n$ equation corresponds to the above equation:

$$
\log y_{i}=\log \beta_{0}+\beta_{1} \log x_{1 i}+\beta_{2} \log x_{2 i}+\ldots+\beta_{k} \log x_{k i}+\log e_{i}, \quad i=1, \ldots, n .
$$


The basic task of forming the regression model in this case is reduced to the estimation of unknown parameters $\log \beta_{0}, \beta_{1}, \beta_{2}, \ldots, \beta_{\mathrm{k}}$, to obtaining the estimated values of the parameters $\log b_{0}, b_{1}, b_{2}, \ldots, b_{k}$, and to forming the model in the form:

$$
\log \hat{y}=\log b_{0}+b_{1} \log x_{1}+b_{2} \log x_{2}+\ldots+b_{k} \log x_{k} .
$$

Determination of model adaptation to empirical data is also performed using the standard error of regression and the coefficient of determination. In order to determine the sense of the dependent variable log $y$ estimation on the basis of each of the independent variables $\log x_{1}, \log x_{2}, \ldots, \log x_{k}$ significance testing of estimated parameters $\log b_{0}, b_{1}, b_{2}, \ldots, b_{k}$ is required.

Transformation of the obtained linear regression model leads to the formation of a nonlinear regression model which is formed to describe behavior of the dependent variable $y$ :

$$
\hat{y}=b_{0} \cdot x_{1}^{b_{1}} \cdot x_{2}^{b_{2}} \cdot \ldots \cdot x_{k}^{b_{k}} .
$$

\section{Artificial Neural Networks Model}

A model based on artificial neural networks consists of interconnected artificial neurons (Fig. 1) that imitate functioning of biological neurons. The signals $x_{1}, x_{2}, \ldots, x_{k}$, which are described by numerical quantities and multiplied by the weighting coefficients $w_{1}, w_{2}, \ldots, w_{k}$, when entering the neuron are summed up analogously to the sum of the potential in the biological neuron body. If the summed number (weighting sum) is above the defined threshold $w_{k+1}$, the neuron produces the output signal $y$. Apart from the threshold, an artificial neuron can have an additional function, the transfer function $f[14]$.

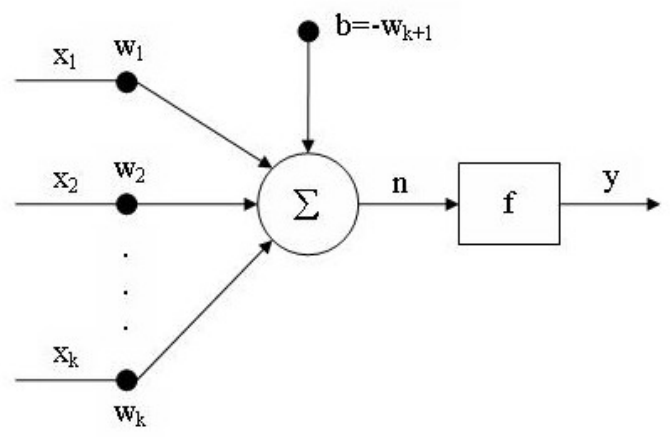

Fig. 1. Artificial neuron

The weighting sum, by adding an input signal $x_{k+1}$ with a fixed value of 1 , can be written in the form:

$$
n=w_{1} x_{1}+w_{2} x_{2}+\ldots+w_{k} x_{k}-w_{k+1} \cdot x_{k+1}=\sum_{i=1}^{k} w_{i} x_{i}+b,
$$

while the output $y$ as the result of the transfer function $f$ can be written in the form:

$$
y=f(n)=f\left(\sum_{i=1}^{k} w_{i} x_{i}+b\right) .
$$

A rather common case seen in practice of establishing a connection between one dependent variable and multiple independent variables requires formation of a model based on artificial neural networks with multiple inputs, a single output, or an output layer, and one or more hidden layers (Fig. 2).

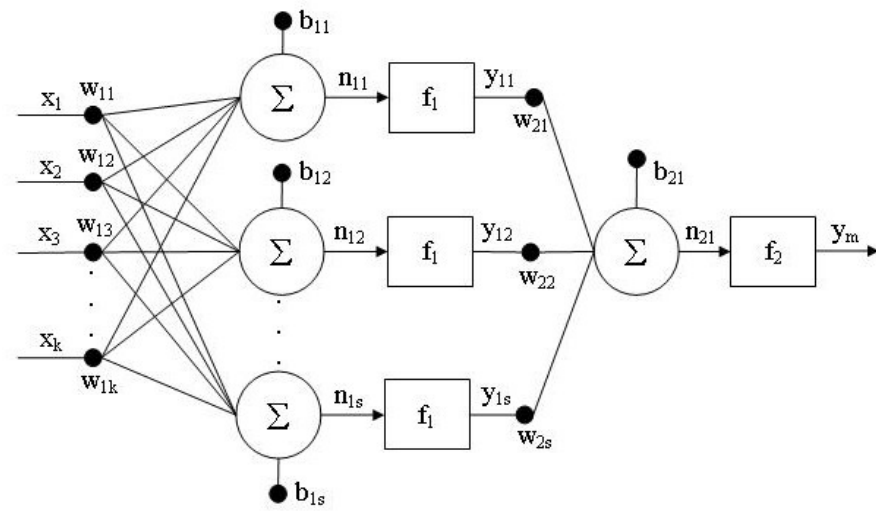

Fig. 2. Artificial neural network model with multiple inputs and one output 
The transfer function can be a linear or non-linear function, and most commonly used transfer functions are linear, jump function and sigmoid transfer function [15].

In order for the neural network to represent non-linear relations, which in practice are most commonly used, it is necessary for the transfer function of its process elements, artificial neurons, to be a nonlinear function of its inputs. The function that fulfills this condition is a sigmoid transfer function [14].

Artificial neural networks require training, i.e. application of algorithms that adjust the amounts of weighting coefficients whereby a very popular Backpropagation learning algorithm for multilayer artificial neural networks, developed in the MATLAB software package, is used.

\section{EXPERIMENT DESIGN}

In this paper the Taguchi orthogonal experiment plan $\mathrm{L}_{9}$ [16], given in Table I, with nine combinations of machining process parameters, was used.

TABLE I. Ortogonal Matrix L 9

\begin{tabular}{||c|c|c|c|c||}
\hline \multirow{2}{*}{ Com. No. } & \multicolumn{5}{|c|}{ Factors } \\
\cline { 2 - 5 } & $\mathbf{X}_{\mathbf{1}}$ & $\mathbf{X}_{\mathbf{2}}$ & $\mathbf{X}_{\mathbf{3}}$ & $\mathbf{X}_{\mathbf{4}}$ \\
\hline \hline 1. & 1 & 1 & 1 & 1 \\
\hline 2. & 1 & 2 & 2 & 2 \\
\hline 3. & 1 & 3 & 3 & 3 \\
\hline 4. & 2 & 1 & 2 & 3 \\
\hline 5. & 2 & 2 & 3 & 1 \\
\hline 6. & 2 & 3 & 1 & 2 \\
\hline 7. & 3 & 1 & 3 & 2 \\
\hline 8. & 3 & 2 & 1 & 3 \\
\hline 9. & 3 & 3 & 2 & 1 \\
\hline
\end{tabular}

The experiment was conducted using twist drills (TD) DIN 338 Ø3, DIN 338 Ø5 and DIN 338 Ø8 made of high-speed steel C.7680 (EN HS6-5-2) the chemical composition of which is given in Table II. The drills were produced by grinding technology and thermally machined to 64-68 HRC hardness, in black versions with normal blade (NB), manufactured by „Swisslion Industrija Alata, a.d.Trebinje“.

TABLE II. Chemical Composition of Steel Č.7680 (EN HS6-5-2) [\%]

\begin{tabular}{||c|c|c|c|c|c|c|c|c||}
\hline \hline $\mathbf{C}$ & W & Mo & Cr & V & Si & Mn & P & S \\
\hline \hline $0,82-0,9$ & $5,5-6,75$ & $4,5-5,5$ & $3,8-4,4$ & $1,75-2,2$ & $0,2-0,45$ & $0,15-0,4$ & $\leq 0,03$ & $\leq 0,03$ \\
\hline
\end{tabular}

The input parameters of the drilling operation were the nominal diameter of the twist drill $(d)$, speed $(n)$, the feed $(f)$, and the angle of installation of the workpiece $(\varepsilon)$ was taken as an additional parameter.

Variation of the speed and feed was adopted based on the recommendation of the twist drills manufacturer. The adopted values of the experiment factors, the nominal diameter, the speed, the feed and the angle of installation of the test tube are given in Table III.

TABLE III. Experiment Factors Values

\begin{tabular}{|c|c|c|c|c||}
\hline \hline No. & $\mathbf{d ~ ( m m )}$ & $\mathbf{n ~ ( o / m i n )}$ & $\mathbf{f ~ ( m m / r e v )}$ & $\left.\boldsymbol{\varepsilon} \mathbf{(}^{\mathbf{0}}\right)$ \\
\hline \hline 1. & 3 & 300 & 0,03 & 0 \\
\hline 2. & 5 & 500 & 0,05 & 3 \\
\hline 3. & 8 & 800 & 0,10 & 5 \\
\hline
\end{tabular}

Material used in experiment for the test tubes was enhancement steel Č.4732 (EN 42CrMo4) thermally treated to $28 \mathrm{HRC}$ hardness with chemical composition given in Table IV.

TABLE IV. Chemical Composition of Steel Č.4732 (EN 42CrMo4) [\%]

\begin{tabular}{||c|c|c|c|c|c|c||}
\hline $\mathbf{C}$ & Si & Mn & P & S & Cr & Mo \\
\hline \hline $0,38-0,45$ & $0,15-0,4$ & $0,5-0,8$ & $\leq 0,035$ & $\leq 0,035$ & $0,9-1,2$ & $0,15-0,3$ \\
\hline
\end{tabular}


The dimensions of the test tubes determined on the basis of the planned drilling depth of $l=3 d$ are given in Table V.

TABLE V. Dimensions of the Test Tubes

\begin{tabular}{|c|c|c|c||}
\hline Twist drill & l (mm) & Test tube diameter $(\mathbf{m m})$ & Test tube thickness (mm) \\
\hline \hline DIN 338 Ø 3,00 & 9 & & 15 \\
\cline { 1 - 2 } DIN 338 Ø 5,00 & 15 & $\varnothing 60$ & 20 \\
\cline { 1 - 2 } DIN 338 Ø 8,00 & 24 & & 30 \\
\hline
\end{tabular}

The experiment was conducted on the EMCO MILL 250 milling machine with the possibility of achieving a maximum speed of the main spindle of $10000 \mathrm{rpm}$ with the axis velocity range of $0-10 \mathrm{~m} / \mathrm{min}$, the possibility of achieving a maximum torque of $41 \mathrm{Nm}$, and EMCO WinNC numerical control with SIEMENS Sinumerik 810/840D software.

To determine the size of the twist drill flank wear an optical device GÜHRING PG 100 was used for measuring the geometric elements of twist drills with the possibility of digital reading of the measured values.

Measurement of the axial drilling force during the operation was conducted by KISTLER measuring chain for measuring axial force and torque with a measuring range up to $20 \mathrm{kN}$.

The mean arithmetic deviation values of the machined surface roughness profile was determined by using the measuring instrument SURTRONIC 25 produced by TAYLOR HOBSON with a measuring range up to $300 \mu \mathrm{m}$.

\section{EXPERIMENT RESULTS}

Having performed the experiment by drilling holes with depth $l=3 d$ for different parameters of the machining operation (nominal diameter, speed, feed and the angle of installation of the workpiece), the values of the axial drilling force $F_{3}(N)$ and the mean arithmetic deviation of the surface roughness profile $R_{a}(\mu m)$ for different twist drills wear levels have been obtained. The values obtained are given in Table VI.

TABLE VI. Experiment Resuts

\begin{tabular}{|c|c|c|c|c|c|c|c|c|c|c|}
\hline \multirow{2}{*}{ No. } & \multirow{2}{*}{$\begin{array}{c}\mathrm{d} \\
(\mathrm{mm})\end{array}$} & \multirow{2}{*}{$\begin{array}{c}\mathbf{n} \\
(\mathbf{0} / \mathbf{m i n}) \\
\end{array}$} & \multirow{2}{*}{ f $(\mathrm{mm} / \mathrm{rev})$} & \multirow{2}{*}{$\varepsilon\left(\left(^{0}\right)\right.$} & \multicolumn{2}{|c|}{$\mathrm{VB}=0 \mathrm{~mm}$} & \multicolumn{2}{|c|}{$V B=0,02 d$} & \multicolumn{2}{|c|}{$V B=0,04 d$} \\
\hline & & & & & $F_{3}(N)$ & $R_{a}(\mu \mathrm{m})$ & $F_{3}(N)$ & $R_{a}(\mu \mathrm{m})$ & $F_{3}(N)$ & $R_{a}(\mu \mathrm{m})$ \\
\hline 1. & 3 & 300 & 0,03 & 0 & 243,21 & 0,306 & 348,88 & 0,675 & 410,28 & 0,960 \\
\hline 2. & 3 & 500 & 0,05 & 3 & 329,62 & 0,411 & 445,86 & 1,23 & 517,12 & 1,41 \\
\hline 3. & 3 & 800 & 0,10 & 5 & 724,04 & 2,61 & 775,32 & 3,25 & 874,82 & 3,71 \\
\hline 4. & 5 & 300 & 0,05 & 5 & 724,67 & 0,702 & 737,62 & 0,825 & 989,43 & 1,53 \\
\hline 5. & 5 & 500 & 0,10 & 0 & 1059,7 & 2,58 & 1271,49 & 2,88 & 1296,40 & 3,25 \\
\hline 6. & 5 & 800 & 0,03 & 3 & 407,76 & 1,54 & 412,21 & 1,81 & 416,65 & 2,07 \\
\hline 7. & 8 & 300 & 0,10 & 3 & 1817,08 & 3,08 & 1842,61 & 3,24 & 2028,99 & 3,85 \\
\hline 8. & 8 & 500 & 0,03 & 5 & 710,80 & 1,88 & 1017,82 & 2,99 & 1040,07 & 4,00 \\
\hline 9. & 8 & 800 & 0,05 & 0 & 832,14 & 2,86 & 867,66 & 3,29 & 965,86 & 4,46 \\
\hline
\end{tabular}

\section{VI.MODELS DEVELOPMENT}

The experimental results for $V B=0,02 d$ were used along with the values of the parameters $b_{0}, \ldots, b_{5}$ obtained by means of the least squares method to form a model of multiple linear regression (MLRM):

$$
\hat{R}_{a}=b_{0}+b_{1} \cdot d+b_{2} \cdot n+b_{3} \cdot s+b_{4} \cdot \varepsilon+b_{5} \cdot F_{3} .
$$

The parameters of the model with standard regression error $s$, the coefficient of determination $R^{2}$, the adjusted coefficient of determination $\bar{R}^{2}$ and the standard parameter error $S_{b_{j}}(j=1, \ldots, 5)$ are given in Table VII. 
TABLE VII. Multiple Linear Regression Model Parameters with Axial Drilling Force for TD NB Variant Drilling in the Test Tubes 28 HRC Hardness

\begin{tabular}{|c|c|c|c|c|}
\hline Model parameter & Parameter value & $\mathbf{S}_{\mathbf{b}_{\mathbf{j}}}$ & $\mathbf{t}_{\mathbf{j}}=\frac{\mathbf{b}_{\mathbf{j}}}{\mathbf{S}}$ & $\mathbf{s}$ \\
\hline & & & & 0,515631635 \\
\hline $\mathrm{b}_{0}$ & $-1,247352303$ & - & $\overline{-1}$ & \multirow{2}{*}{$\mathbf{R}^{2}$} \\
\hline $\mathrm{b}_{1}$ & $-0,06714737$ & 0,083646497 & $-0,802751737$ & \\
\hline $\mathrm{b}_{2}$ & 0,003859932 & 0,000836465 & 4,614576426 & 0,918200815 \\
\hline$b_{3}$ & $-6,79879202$ & 5,838378579 & $-1,164500028$ & \multirow{2}{*}{$\overline{\mathbf{R}}^{2}$} \\
\hline $\mathrm{b}_{4}$ & $-0,002993561$ & 0,083646497 & $-0,035788237$ & \\
\hline$b_{5}$ & 0,002572038 & 0,000382718 & 6,720446502 & 0,781868839 \\
\hline
\end{tabular}

Given that all the values $\left|t_{j}\right|<t$ for the significance level $p=0,001$, the estimation of the dependent variable $R_{a}$ based on the variables $d, n, f, \varepsilon$ and $F_{3}$ makes sense.

After the formation of the multiple linear regression model, a transformed multiple nonlinear regression model is formed as follows:

$$
\log \hat{R}_{a}=\log b_{0}+b_{1} \log d+b_{2} \log n+b_{3} \log s+b_{4} \log \varepsilon+b_{5} \log F_{3} .
$$

The parameters of the transformed model with standard regression error $s$, the coefficient of determination $R^{2}$, the adjusted coefficient of determination $\bar{R}^{2}$ and the standard parameter error $S_{b_{j}}(j=1, \ldots, 5)$ are given in Table VIII.

TABLE VIII. Transformed Regression Model Parameters with Axial Drilling Force for TD NB Variant Drilling in the Test Tubes 28 HRC Hardness

\begin{tabular}{|c|c|c|c|c|}
\hline \multirow{2}{*}{ Model parameter } & \multirow{2}{*}{ Parameter value } & \multirow{2}{*}{$\mathbf{S}_{\mathbf{b}_{\mathbf{j}}}$} & \multirow{2}{*}{$\mathbf{t}_{\mathbf{j}}=\frac{\mathbf{b}_{\mathbf{j}}}{\mathbf{S}_{\mathbf{b}_{\mathbf{j}}}}$} & $\mathbf{s}$ \\
\hline & & & & 0,106950387 \\
\hline$\overline{\log b_{0}}$ & -6,509728393 & - & - & \multirow{2}{*}{$\mathbf{R}^{2}$} \\
\hline $\mathrm{b}_{1}$ & $-0,334062021$ & 0,204943271 & $-1,630021905$ & \\
\hline $\mathrm{b}_{2}$ & 1,046248025 & 0,204943271 & 5,105061606 & 0,943310952 \\
\hline$b_{3}$ & $-0,322109369$ & 0,166372743 & $-1,936070551$ & \multirow{2}{*}{$\overline{\mathbf{R}}^{2}$} \\
\hline $\mathrm{b}_{4}$ & $-0,000393794$ & 0,007885879 & $-0,049936587$ & \\
\hline$b_{5}$ & 1,320569484 & 0,158404252 & 8,33670475 & 0,848829204 \\
\hline
\end{tabular}

Transformation of the obtained model resulted in the multiple nonlinear regression model (MNRM) with axial drilling force for twist drill drilling operation in $28 \mathrm{HRC}$ hardness test tubes:

$$
\hat{R}_{a}=b_{0} \cdot d^{b_{1}} \cdot n^{b_{2}} \cdot s^{b_{3}} \cdot \varepsilon^{b_{4}} \cdot F_{3}^{b_{5}} .
$$

Formation of the model based on artificial neural networks (ANNM) with multiple inputs (nominal diameter of the twist drill, the speed, the feed, the angle of installation of the workpiece, and axial force) and one output (the mean arithmetic deviation of surface roughness) was conducted using the Backpropagation artificial neural network with two hidden layers with sigmoidal transfer functions and a linear transfer function in the output layer.

Training, validation and testing of the neural network was performed with input combinations of the machining process parameters and the axial drilling force obtained for twist drills flank wear values of $V B=0$ $m m$ and $V B=0,04 d$. The least errors in training, validation and testing were achieved by a neuron network of 15 neurons in the first hidden layer, 10 neurons in the second hidden layer (Fig. 3), and the learning function LEARNGDM. 


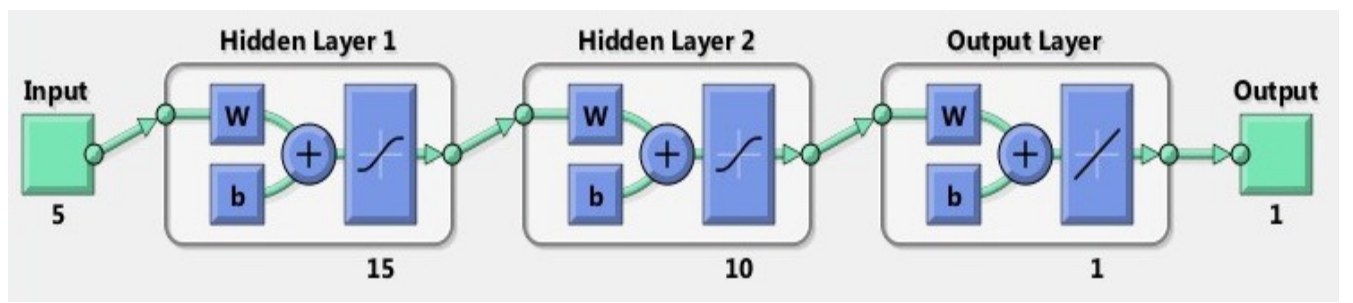

Fig. 3. Architecture of trained artificial neural network

Based on all input combinations and values of the axial drilling force obtained for the twist drills wear values of $V B=0,02 d$ the trained artificial neural network was simulated. Comparative results of the experiment, regression models and the results obtained by simulating the trained artificial neural network are given in Table IX.

TABLE IX. Comparative Analysis of the Experiment Results and Models with Axial Drilling Force for TD NB Variant Drilling in the Test Tubes 28 HRC Hardness

\begin{tabular}{|c|c|c|c|c|c|c|c|}
\hline \multirow{2}{*}{ No. } & \multirow{2}{*}{$\mathbf{R}_{\mathrm{a}}(\mu \mathrm{m})$} & \multicolumn{3}{|c|}{$R_{a}(\mu m)-$ Model results } & \multicolumn{3}{|c|}{ Model error (\%) } \\
\hline & & MLRM & MNRM & ANNM & MLRM & MNRM & ANNM \\
\hline 1. & 0,675 & 0,402553725 & 0,594873774 & 0,70322 & 40,362411 & 11,870552 & 4,180740741 \\
\hline 2. & 1,23 & 1,279019702 & 1,180354138 & 1,047 & 3,9853417 & 4,03624891 & 14,87804878 \\
\hline 3. & 3,25 & 2,938455912 & 3,2050161 & 3,0198 & 9,585972 & 1,38411998 & 7,083076923 \\
\hline 4. & 0,825 & 1,117169202 & 1,133513045 & 0,7506 & 35,414449 & 37,3955206 & 9,018181818 \\
\hline 5. & 2,88 & 2,937317373 & 3,203898677 & 3,1618 & 1,9901866 & 11,2464818 & 9,784722222 \\
\hline 6. & 1,81 & 2,352131193 & 1,729480948 & 1,7266 & 29,952 & 4,44856643 & 4,607734807 \\
\hline 7. & 3,24 & 3,423850341 & 2,59668921 & 3,1769 & 5,6743932 & 19,8552713 & 1,947530864 \\
\hline 8. & 2,99 & 2,544374144 & 2,981757721 & 3,8302 & 14,903875 & 0,2756615 & 28,10033445 \\
\hline 9. & 3,29 & 3,195128408 & 3,379469916 & 3,2673 & 2,883635 & 2,71945034 & 0,689969605 \\
\hline \multicolumn{5}{|c|}{ Model mean error (\%) } & 16,083585 & 10,359097 & 8,921148912 \\
\hline
\end{tabular}

\section{CONCLUSION}

Besides its dependence on the input parameters of the machining operations, the quality of the machined surface, which is most often monitored through the mean arithmetic deviation of the surface roughness profile, depends on the machining tool wear level which can be indirectly monitored by measuring the parameters correlated with the tool wearing (the force, the torque, the acoustic emission level).

Development of multiple regression models and the model based on artificial neural networks, which establish the connection between the input parameters of the machining process and the tool wear on one side and the machined surface quality on the other by using indirect parameters, enables prediction of the machined surface quality during machining process based on the information about the parameters in correlation with the tool wear.

Comparative analysis of the developed prediction models leads to the conclusion that the model based on artificial neural networks gives the best results.

\section{REFERENCES}

[1] A. Çiçek, T. Kivak and G. Samtaş, ,Application of Taguchi Method for Surface Roughness and Roundness Error in Drilling of AISI 316 Stainless Steel“, Strojniški vestnik - Journal of Mechanical Engineering, vol. 58, no. 3, 2012, pp. 165-174

[2] L.L.R. Rodrigues, A.N. Kantharaj, B. Kantharaj, W.R.C. Freitas and B.R.N. Murthy, „Effect of Cutting Parameters on Surface Roughness and Cutting Force in Turning Mild Steel“, Research Journal of Recent Sciences, vol. 1, no.10, 2012, pp. 19-26

[3] B.V. Raghunandan, S.L. Bhandarkar and K.S. Pankaj, „An Experimental Mathematical Modelling of Surface Roughness in Turning Operation of En19 with Carbide Tool“, International Journal of Mechanical Engineering and Research, vol. 3, no. 5, 2013, pp. 495-502

[4] F. Ficici, S. Koksal and M.C. Karacadag, „Optimization of Cutting Parameters for Surface Roughness of Stainless Steel in Drilling Process“, International Journal of Science and Advanced Technology, vol. 2, no. 3, 2012, pp. 114-121

[5] A. Rashid and A. Lani, „Surface Roughness Prediction for CNC Milling Process using Artificial Neural Network“, In Proceedings of the World Congress on Engineering, London, 2010.

[6] G. Šimunović, T. Šarić and R. Lujić, „Application of neural networks in assessing the quality of the machined surface“, Tehnički vjesnik, vol. 16, no. 2, 2009, pp. 43-47

[7] M.N. Konanki and R.R. Sadineni, „ANN Based Surface Roughness Prediction In Turning Of AA 6351“, International Journal of Engineering Research and Applications, vol. 3, issue 4, 2013, pp.1455-1459

[8] B. Nedić, B. Tadić and Z. Đorđević, ,Some results of testing the impact of the tool wear on cutting forces and the machined surface quality“, Tribology in industry, no. 4, 1991, pp. 107-114 
[9] O. Spaić and B. Marinović, „Influence of Wearing Drills on Drilling Axial Force“, 1st International Scientific Conference Cometa 2012, Jahorina

[10] Y. Xu, K. Hiroyuki and Z. Wei, „Back Propagation Wavelet Neural Network Based Prediction of Drill Wear from Thrust Force and Cutting Torque Signals“, Computer and Information Science, vol. 2, no. 3, 2012, pp. 75-86

[11] M. Lovroć, J. Komić and S. Stević, ,„Statistical analysis - methods and application“, Faculty of Economics, Banja Luka, 2006.

[12] M. Kostić, „Methods of statistical analysis“, Senior Business School Belgrade, Belgrade, 1996.

[13] M. Mijanović, „Statistical methods in anthropological sciences“, University of Montenegro, Podgorica, 1997.

[14] B. Dalbelo - Bašić, M. Čupić and J. Šnajder, „Artificial neural networks“, Faculty of Electrical Engineering and Computing, Zagreb, 2008.

[15] T.M. Hagan, B.H. Demuth, H.M. Beale, O. De Jesús, „Neural Network Design“, 2nd Edition, eBook, Available at: http://hagan.okstate.edu/NNDesign.pdf (Downloaded: 25 January 2018)

[16] M. Cavazzuti, „Optimization Methods: From Theory to Design“, Springer-Verlag Berlin Heidelberg, 2013.

\section{AUTHORS PROFILE}

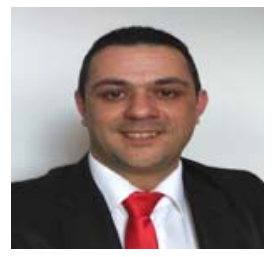

Radoslav Vučurević, M.Sc, was born on 1980 in Trebinje, Bosnia and Herzegovina. He graduated in 2007 and received a M.Sc. in 2012 at Production and Management Faculty Trebinje, University of East Sarajevo. The theme of the thesis was "Increasing the process capability level by means of quality tools". He is a teaching assistant, in the scientific field of Mechanical Engineering, at the Production and Management Faculty Trebinje. He is the author and co-author of 12 scientific and research papers published in national and international journals and scientific conferences. He participated in the realization of 1 scientific-research project.

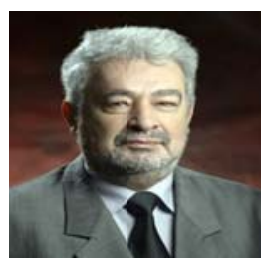

Zdravko Krivokapić, $\mathrm{PhD}$, a full professor of Faculty of Mechanical Engineering in Podgorica, was born on 1958 in Nikšić. He graduated in 1981 at Faculty of Mechanical Engineering, University of Montenegro, Department of Production Engineering. Master's thesis entitled "Planning and inventory management of spare parts" has publicly defended in 1989 at the Department of Production Engineering within Faculty of Mechanical Engineering in Belgrade. He received his PhD in 1993 from the Faculty of Mechanical Engineering in Podgorica. The theme of the thesis was "Contribution to the design of automatic technological process of cutting through expert-system". He is a president of the Organizing Committee and member of the Program Advisory of SQM Conference and International Conferences ICQME. He is an editor of the international journal International Journal for Quality Reserch, indexed in the Scopus database, which has been published since 2007. He is a member of the program committee of 4 magazines and 13 international conferences. In the context of scientific research, he published more than 250 papers in international journals, national journals, international conferences and national conferences. He is the author of 16 books/textbooks and 13 scripts. As a manager has implemented 8 scientific research projects and 17 professional projects. He is a member of the American Society for Quality (ASQ).

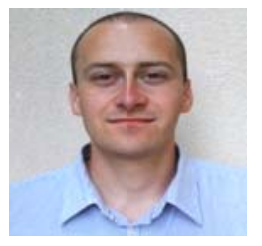

Radislav Brđanin, M.Sc, was born on 1987 in Foča, Bosnia and Herzegovina. He graduated in 2010 and received a M.Sc. in 2013 at Production and Management Faculty Trebinje, University of East Sarajevo. The theme of the thesis was "Development of multiple output neural network models". He is a teaching assistant, in the scientific field of Mechanical Engineering, at the Production and Management Faculty Trebinje. He is the author and co-author of 6 scientific and research papers published in national and international journals and scientific conferences. He participated in the realization of 2 scientific-research projects. 